\title{
Effects of long-term construction noise on health of adult female Wistar rats
}

\author{
J. Zymantiene', R. Zelvyte ${ }^{1,3}$, I. Pampariene ${ }^{1}$, A. Aniuliene ${ }^{2}$, \\ N. Juodziukyniene ${ }^{2}$, J. Kantautaite ${ }^{3}$, V. Oberauskas ${ }^{1}$ \\ ${ }^{1}$ Department of Anatomy and Physiology, Veterinary Academy, \\ Lithuanian University of Health Sciences, Tilzes 18, LT-47181 Kaunas, Lithuania \\ ${ }^{2}$ Department of Veterinary pathobiology, Veterinary Academy, \\ Lithuanian University of Health Sciences, Tilzes 18, LT-47181 Kaunas, Lithuania \\ ${ }^{3}$ Research Center of Digestive Physiology and Pathology, Veterinary Academy, \\ Lithuanian University of Health Sciences, Tilzes 18, LT-47181 Kaunas, Lithuania
}

\begin{abstract}
The aim of this study was to investigate the influence of long-term building construction noise from refurbishment, which including vibration, on some physiological parameters and histopathological changes of organs of Wistar rats. Twenty 12 month old female rats were divided into two groups: rats group I $(n=10)$ were exposed to long-term construction noise and rats group II $(n=10)$ were kept under normal noise level. Study results revealed that long-term construction noise from building refurbishment has an influence on body weight, haematological and some serum biochemical parameters affects caecal microbiota, and causes histopathological changes in the organs of adult female Wistar rats. It was noticed that rats in group I exihibited significantly higher mean values for total protein, albumin and lower values for glucose, AST, ALT, blood urea nitrogen, haematological and caecal microbiota parameters than rats in group II. The most common pathologies were determined in the kidney, liver and lungs. Other observed pathologies were lymphadenopathy, catarrhal inflammation of the intestines, spleen hyperplasia and mammary gland adenofibroma. Single cases were subcutaneous fibroma in the thoracic region, abortus with uterine inflammation and thymus hyperplasia with formation of cysts were found.
\end{abstract}

Key words: Wistar rat, weight, blood, caecal microbiota, histopathology

\section{Introduction}

Human interaction and physical environmental factors are part of the stimuli presented to laboratory animals every day, influencing their behaviour and physiology and contributing to their welfare (Castelhano-Carlos and Baumans 2009). The concept of the five freedoms (freedom from thirst, hunger and malnutrition, freedom from discomfort, freedom from pain, injury and disease, freedom to express normal behavior and freedom from fear and distress) should be applied to achieve animal's welfare.

Cage cleaning and design, bedding materials, nutrition, light intensity, noise, and veterinary care effect 
laboratory rodent behaviours, physiology, health and welfare. The effects of sound on animal physiology and behavior depend not only on its intensity (or loudness), which is measured in decibels (dB), its frequency, which is measured in hertz $(\mathrm{Hz})$, and its duration and pattern (including vibration potential), but also on the hearing ability of the animal species and strain, the age and physiological state of the animal at the time of exposure, to what sounds the animal has been exposed during its lifetime (noise exposure history of the animal) and to the predictability of the acoustic stimulus (Clough 1982, Gamble 1982, Voipio 1997, Turner et al. 2005, Burn 2008). Meaningful sounds at relatively low-intensity levels can have a considerable impact on animal physiology and behaviour by engaging limbic structures and higher centers involved in determining context and meaning (Turner et al. 2005).

Rodents have a different spectrum of audible sounds with maximum sensitivity at frequencies that are inaudible to humans. Humans can perceive frequencies from $20 \mathrm{~Hz}$ to $20 \mathrm{kHz}$, the frequencies from $400 \mathrm{~Hz}$ to $4.8 \mathrm{kHz}$ being important for speech. Rodents not only produce sounds that we can hear, but also produce and hear frequencies that are inaudible to humans (above $20 \mathrm{kHz}$ ), perceiving sounds up to 80 kHz (Kelly and Masterton 1977, Bjork et al. 2000, Turner et al. 2005).

Exposure to high levels of noise can create physical and psychological stress and reduce productivity (Ng 2000). The negative impact of building construction noise from demolition and refurbishment on human health is well known (Suter 2002, Leensen et al. 2011). Most investigations have focused on human hearing, but the effects of sound do not stop with the ears. Non auditory effects of noise exposure are those effects that do not cause hearing loss but can still change the normal processes of other organ systems, such as the cardiovascular and digestive systems.

Regarding noise influences on laboratory animal physiology and behaviour, both auditory (hearing damage) and non auditory effects have been reported and reviewed in the literature (Voipio 1997, Burn 2008). Intense noise exposure can damage the cochlea and inner ear and lead to a cascade of auditory effects along the entire central auditory cascade (Turner et al. 2005). However, during a one year period of neighboring building refurbishment changes in rat behaviour (lethargy), coat appearance and litter size were noted. There is no information on low long-term construction noise exposure of Wistar rats may affect their health.

The aim of this study was to investigate the influence of long-term building construction noise from refurbishment, which includes vibration, on some physiological parameters and histopathological changes of organs of Wistar rats.

\section{Materials and Methods}

\section{Experiment conditions and experimental animals}

Wistar strain rats were kept in two different premises (No. 1 and No. 2) under the same normal conditions: light-dark cycle of 12:12 hours, temperature maintained at $22 \pm 2^{\circ} \mathrm{C}$ and relative humidity was 55 $\pm 5 \%$. Rats were given ad libitum access to high-quality feed of the same batch and water throughout the whole study. The commercial standard diet (PA-11700000-171) for rodents contained crude protein $19.91 \%$, fat $12.05 \%$, and crude fiber $2.79 \%$ and $7.72 \%$ cellulose in $1 \mathrm{~kg}$ of feed. All procedures were approved by the local Animal Ethical Committee (No. license G2-16).

The rats were housed in standard polycarbonate cages (Techniplast, Italy), where minimum enclosure size was $800 \mathrm{~cm}^{2}$, floor area per animal $350 \mathrm{~cm}^{2}$ and minimum $18 \mathrm{~cm}$ height according to Directive 2010/63 EU of the European Parliament and of the Council of 22 September 2010 on the protection of animals used for scientific purposes.

The three-storey building under refurbishment was only 10 meters away from Wistar rat premises No. 1. Refurbishment works started early in the morning and continued until late afternoon five days a week and work lasted for about one year. Five days a week construction noise from electric drills, electric saws, grinders, cutting hammers and other devices ranged from 87 to $120 \mathrm{~dB}$ and the vibration level was $\mathrm{A}(8)$ $=4 \mathrm{~m} / \mathrm{s}^{2}$ for two years.

Immediately after the refurbishment works finished twenty randomly selected 12 -months- old female rats were divided into two groups in accordance with their allocated premises. Rats group I $(n=10)$ were kept in premises No. which is located alongside refurbished building and rats of group II $(\mathrm{n}=10)$ were held in premises No. 2 which is situated approximately 100 meters away from the construction site and the noise level did not exceed $60 \mathrm{~dB}$ at any time ( control group).

\section{Recordings of respiration and body weight}

The respiratory rate was measured by calculating the frequency of respiratory movements per minute (cycles per minute, cpm) in a quiet but awake state (eyes opened, no motor activity). Body weight (g) was then measured using KERN PCB000-1 scales (Germany). 


\section{Blood sampling and analysis}

Rats were killed using an overdose of carbon dioxide in a Quietek ${ }^{\mathrm{TM}} \mathrm{CO}_{2}$ induction system chamber (USA). Trunk blood was collected in plastic tubes containing anticoagulant for haematological analysis and plastic serum tubes for biochemical analysis. Blood samples for haematological analyses were delivered to the laboratory within $1 \mathrm{~h}$ of collection and promptly assayed. Samples for biochemical analyses were centrifuged $(4000 \mathrm{x} \mathrm{g}, 10 \mathrm{~mm})$ in an EBA-200 centrifuge (Germany) and stored at $-20^{\circ} \mathrm{C}$ until analysis.

The red blood cell count (RBC) was calculated using Neubauer's counting chamber (Germany) under an OLYMPUS CX 22LED microscope (Germany). The white blood cell count (WBC) and haemoglobin content $(\mathrm{Hb})$ were analyzed using a QBC Autoread Plus system (QBC Diagnostics Inc., USA).

Serum levels of total protein (T-Pro), albumin (Alb), glucose (Glu), triglycerides (TG), total cholesterol (T-Cho), aspartate aminotransferase (AST), alanine aminotransferase (ALT), blood urea nitrogen (BUN) were analysed using a SPOTCHEM EZ SP-4430 automated biochemical analyser (Arkray Inc., Japan).

\section{Intestinal content sampling and microbiological analysis}

The ceacum was removed aseptically from the abdominal cavity. The specimen was placed on a glass dish and cut open along its longitudinal incision. For microbiological enumeration, the intestinal contents were carefully collected without scraping the mucosa and delivered to the laboratory immediately after sampling.

Caecal contents $(1 \mathrm{~g})$ were homogenized in $9 \mathrm{ml}$ saline peptone water by vortex mixing (IKA mini shaker MS2, USA). Bacteria growing and enumeration was using a standard method. Serial decimal dilutions carried out and as parallel triplicate cultures was inoculated onto Plate count agar (Liofilchem, Italy) for enumeration of aerobic and facultative anaerobic bacteria (LST EN ISO 4833:2003); de Man, Rogosa and Sharpe (MRS) agar (Biolife, Italy) for Lactobacillus spp. (LST ISO 15214:2009); Slanetz and Bartley agar+TTC (Liofilchem, Italy) for enterococci (ISO 7899-2:2000); Violet red bile glucose agar (Liofilchem, Italy) for Enterobacteriaceae (ISO 21528-2:2004).

The plates were incubated under aerobic conditions for growing of aerobic and facultative anaerobic bacteria at $30^{\circ} \mathrm{C}$ for 24 hours; for enterococci at $35^{\circ} \mathrm{C}$ for 48 hours and for Enterobacteriaceae at $37^{\circ} \mathrm{C}$ for 24 hours. Plates for growing of mesophilic Lactobacillus spp. were incubated at $30^{\circ} \mathrm{C}$ in 2.5 -liter jars (Oxoid) under microaerophilic conditions that were created using a CampyGen gas pack (Oxoid) for 72 hours.

The numbers of colony forming units were expressed as $\log _{10} \mathrm{CFU}$ per gram of caecal content $\left(\log _{10} \mathrm{CFU} / \mathrm{g}\right)$.

\section{Histopathological examination}

During necropsy, after macroscopical evaluation, specimens of the following organs were collected: liver, pancreas, spleen, thymus, heart, lungs, stomach, colon, ceacum, and kidney.

Tissue samples were fixed with $10 \%$ formalin solution. Paraffin blocks were made using Shandon Pathcentre (UK) and TES99 Medite Medizintechnik (Germany) equipment. Four micrometer sections were obtained using Shandon Pathcentre (UK) microtome. Sections were stained with hematoxylin-eosin (HE) using Sakura Accu-Cut SRM (Japan) equipment.

\section{Statistical analysis}

Statistical analysis of the results was carried out using the SPSS version 15 (licence No. 9900457; SPSS Inc., Chicago, IL). All data are presented as mean \pm SEM (standard error of the mean). Differences in body weight, respiratory rate, haematological and biochemical parameters among groups were determined using Student's paired $t$ test. Differences in microbiological parameters among groups were compared by one-factor ANOVA. A $p \leq 0.05$ was indicative of a statistically significant difference between groups.

\section{Results}

Body weight of Wistar rats group I, which were exposed to construction noise for one year, was less by $7.5 \%(\mathrm{p}<0.05)$ in compare with rats group II, where the noise level was normal. Respiratory rate did not differ between the groups $(p>0.05)$. The results of body weight and respiratory rate are shown in Table 1.

The results of haematological and biochemical parameters of group I and II rats from are presented in Table 2. The haematological parameters of rats exposed to long-term construction noise (group I) had significantly lower mean values than rats kept under a normal noise level (group II). The number of RBC 
Table 1. Body weight and respiratory rate of Wistar rats exposed to different noise levels.

\begin{tabular}{lcccccc}
\hline \multirow{2}{*}{ Parameter } & \multicolumn{2}{c}{ Group I $(\mathrm{n}=10)$} & \multicolumn{2}{c}{ Group II $(\mathrm{n}=10)$} & \multirow{2}{*}{$\mathrm{p}^{*}$} & \\
\cline { 2 - 5 } & mean & SEM & mean & SEM & $<0.05$ \\
\hline Body weight, $\mathrm{g}$ & 265.97 & 2.13 & 287.52 & 1.8 & $>0.05$ \\
\hline Respiratory rate, cpm & 58 & 1.64 & 60 & 2.31 & $<$ \\
\hline
\end{tabular}

SEM - standard error of the mean

* Student's paired $t$ test

Table 2. Haematological and biochemical parameters of Wistar rats exposed to different noise levels.

\begin{tabular}{|c|c|c|c|c|c|}
\hline \multirow[b]{2}{*}{ Parameter } & \multicolumn{2}{|c|}{ Group I $(\mathrm{n}=10)$} & \multicolumn{2}{|c|}{ Group II $(\mathrm{n}=10)$} & \multirow[b]{2}{*}{$\mathrm{p}^{*}$} \\
\hline & mean & SEM & mean & SEM & \\
\hline $\mathrm{RBC}, \times 10^{12} / \mathrm{L}$ & 3.90 & 0.08 & 4.20 & 0.07 & $<0.05$ \\
\hline $\mathrm{WBC}, \times 10^{9} / \mathrm{L}$ & 5.60 & 0.13 & 8.10 & 0.42 & $<0.05$ \\
\hline $\mathrm{Hb}, \mathrm{g} / \mathrm{L}$ & 111.00 & 0.11 & 117.00 & 0.10 & $<0.05$ \\
\hline T-Pro, g/L & 76.20 & 2.31 & 55.90 & 1.36 & $<0.001$ \\
\hline $\mathrm{Alb}, \mathrm{g} / \mathrm{L}$ & 41.20 & 1.67 & 36.00 & 0.77 & $<0.05$ \\
\hline Glu, mmol/L & 3.31 & 0.74 & 7.52 & 0.38 & $<0.001$ \\
\hline $\mathrm{TG}, \mathrm{mmol} / \mathrm{L}$ & 2.27 & 0.45 & 1.40 & 0.10 & $>0.05$ \\
\hline $\mathrm{T}$-Cho, mmol/L & 1.75 & 0.17 & 1.90 & 0.09 & $>0.05$ \\
\hline AST, IU/L & 140.10 & 9.14 & 187.60 & 11.92 & $<0.01$ \\
\hline ALT, IU/L & 19.60 & 2.34 & 69.10 & 3.58 & $<0.001$ \\
\hline $\mathrm{BUN}, \mathrm{mmol} / \mathrm{L}$ & 6.20 & 0.29 & 8.56 & 0.42 & $<0.001$ \\
\hline
\end{tabular}

SEM - standard error of the mean, RBC - red blood cells, WBC - white blood cells, Hb - haemoglobin, T-Pro - protein, Alb - albumin, Glu - glucose, TG - triglycerides, T-Cho - total cholesterol, AST - aspartate aminotransferase, ALT - alanine aminotransferase, BUN - blood urea nitrogen

* Student's paired $t$ test

Table 3. Microbiological parameters of ceacum content in Wistar rats exposed to different noise levels.

\begin{tabular}{lcccccc}
\hline \multirow{2}{*}{\multicolumn{1}{c}{ Parameter }} & Group I $(\mathrm{n}=10)$ & \multicolumn{2}{c}{ Group II $(\mathrm{n}=10)$} \\
\cline { 2 - 5 } & mean & SEM & mean & SEM & $\mathrm{p}^{*}$ \\
\hline Total count aerobic and facultative anaerobic bacteria, $\log _{10} \mathrm{CFU} / \mathrm{g}$ & 5.52 & 0.12 & 5.87 & 0.15 & $<0.05$ \\
\hline Mesophilic Lactobacillus spp., $\log _{10} \mathrm{CFU} / \mathrm{g}$ & 4.67 & 0.16 & 5.26 & 0.26 & $<0.01$ \\
\hline Enterobacteriaceae, $\log _{10} \mathrm{CFU} / \mathrm{g}$ & 3.75 & 0.11 & 4.11 & 0.25 & $>0.05$ \\
\hline Enterococci, $\log _{10} \mathrm{CFU} / \mathrm{g}$ & 4.03 & 0.2 & 4.63 & 0.23 & $<0.05$ \\
\hline
\end{tabular}

SEM - standard error of the mean, CFU - colony forming units

* one-factor ANOVA

in blood of rats group II was higher by $7.7 \%(\mathrm{p}<0.05)$, WBC by $44.6 \%(\mathrm{p}<0.05)$ and the concentration of $\mathrm{Hb}$ by $5.4 \%(\mathrm{p}<0.05)$ in compare to the rats group I.

As seen in Table 2, the group I rats exhibited significantly higher mean values for T-Pro, Alb and significantly lower values for Glu, AST, ALT and BUN than rats group II. The mean of serum T-Pro and Alb in rats exposed to excessive noise (group I) were higher by $36.31 \%(\mathrm{p}<0.001)$ and $14.44 \%(\mathrm{p}<0.05)$, respectively, compared to the rats group II. The mean of Glu content in blood of rats group I was lower by $55.9 \%$, BUN by $27.57 \%$, AST by $25.3 \%$ and ALT by $71.64 \%$ than rats kept under normal noise level (group II). Differences in mean values of TG and T-Cho concentration in serum between groups were not observed.

Some variation of caecal microbiota are shown in Table 3. The total count of aerobic and facultative anaerobic bacteria, Lactobacillus spp. and enterococci in caecal content of rats exposed to long-term noise were statistically significantly lower by $5.96 \%$ 


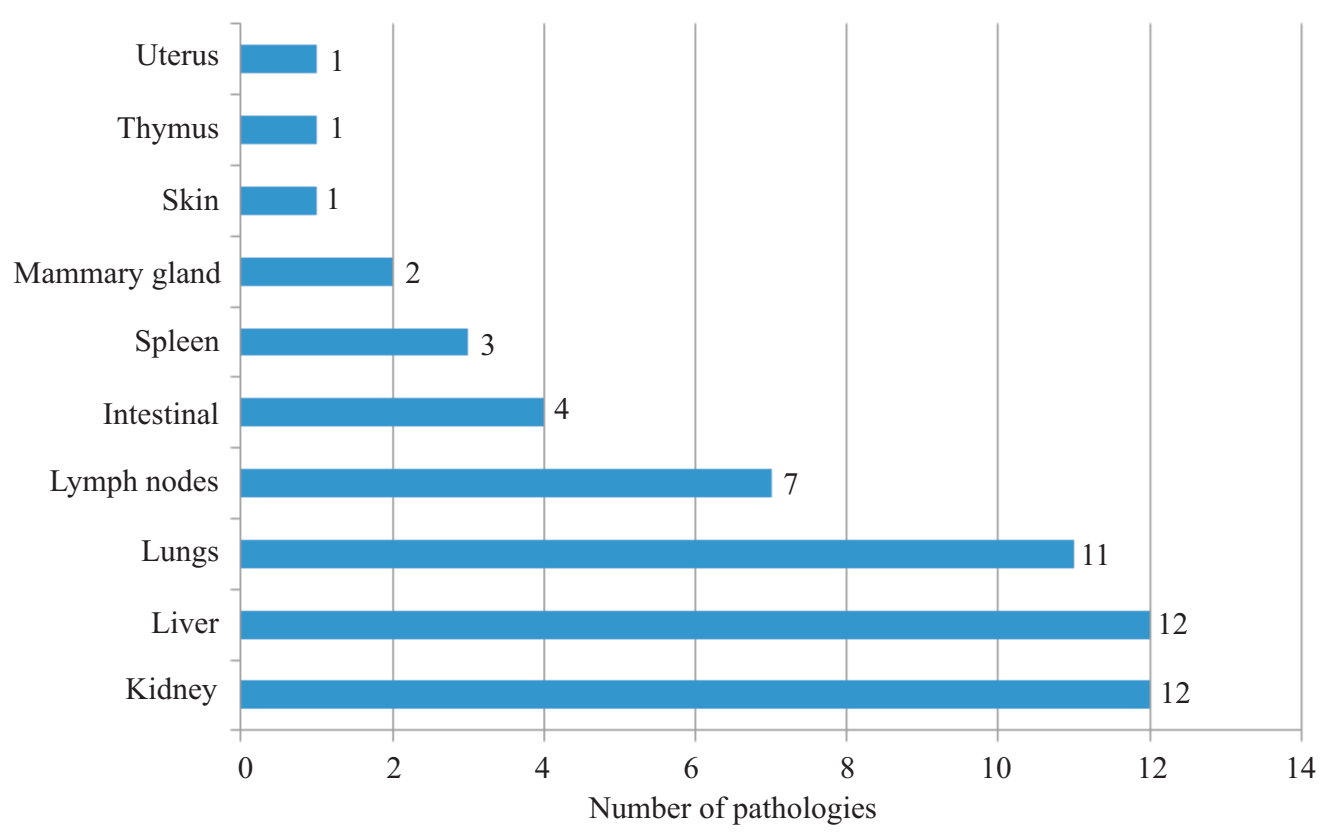

Fig. 1. The total number of pathologies / frequency Wistar rat organ systems.

Table 4. Distribution of the number of pathologies among different rats.

\begin{tabular}{|c|c|c|c|c|c|c|c|c|c|c|c|}
\hline \multirow{2}{*}{ Rat } & \multicolumn{11}{|c|}{ Pathologies } \\
\hline & Lungs & Kidney & Liver & Intestinal & Spleen & Thymus & $\begin{array}{l}\text { Lymph } \\
\text { nodes }\end{array}$ & Skin & $\begin{array}{l}\text { Mammary } \\
\text { gland }\end{array}$ & Uterus & Total \\
\hline 1 & 1 & 2 & 1 & 0 & 0 & 0 & 0 & 1 & 0 & 0 & 5 \\
\hline 2 & 2 & 2 & 2 & 0 & 1 & 0 & 1 & 0 & 1 & 0 & 9 \\
\hline 3 & 1 & 1 & 2 & 0 & 0 & 0 & 1 & 0 & 0 & 0 & 5 \\
\hline 4 & 1 & 2 & 1 & 1 & 1 & 0 & 1 & 0 & 1 & 0 & 8 \\
\hline 5 & 1 & 0 & 1 & 1 & 1 & 0 & 1 & 0 & 0 & 0 & 5 \\
\hline 6 & 0 & 0 & 0 & 0 & 0 & 0 & 0 & 0 & 0 & 0 & 0 \\
\hline 7 & 2 & 3 & 2 & 0 & 0 & 0 & 1 & 0 & 0 & 1 & 9 \\
\hline 8 & 0 & 0 & 1 & 0 & 0 & 0 & 0 & 0 & 0 & 0 & 1 \\
\hline 9 & 2 & 1 & 1 & 1 & 0 & 0 & 1 & 0 & 0 & 0 & 6 \\
\hline 10 & 1 & 1 & 1 & 1 & 0 & 1 & 1 & 0 & 0 & 0 & 6 \\
\hline
\end{tabular}

$(\mathrm{p}<0.05), 11.22 \%(\mathrm{p}<0.01)$ and $12.96 \%(\mathrm{p}<0.05)$, respectively, compared to the rats kept under normal noise level.

During histopathological examination the most common pathologies where determined in the kidney, liver and lungs. They are presented in Fig. 1.

In addition to these pathologies common pathologies were lymphadenopathy, catarrhal inflammation of the intestines (Fig. 1), spleen hyperplasia (Fig. 2) and mammary gland adenofibroma (Fig. 3). Only one case was of subcutaneous fibroma in the thoracic region (Fig. 4), one of uterine inflammation (Fig. 5), and one case of thymus hyperplasia and cyst formation (Fig. 6) were determined in histopathological examination.
In Table 4 the data show that only one rat did not have any pathology. One rat had only one pathology, swelling of the liver. Other rats had different pathologies (from 5 to 9 ).

The most common rat lung pathologies were pneumonia and emphysema (each $36.4 \%$ ), congestion $(18.2 \%)$, and edema $(9.1 \%)$.

Histologically (Fig. 7) there were damaging of lung tissue, infiltration of neutrophils and macrophages and, as a consequence of inflammation we determined bronchiectasis (Fig. 8), cholesterol crystals (Fig. 9), granulation tissue formation (Fig. 10) and emphysema (Fig. 11).

Frequently, rat kidney pathologies were vacuolation of podocytes (58.3\%) and kidney swelling 


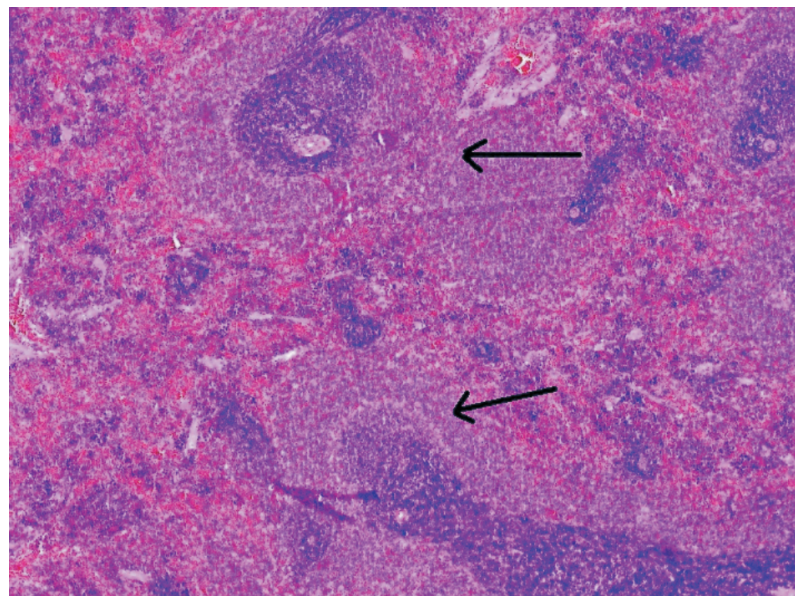

Fig 1. Enlarged white pulp (lymphoid follicles) in rat spleen (arrows). HE, x40.

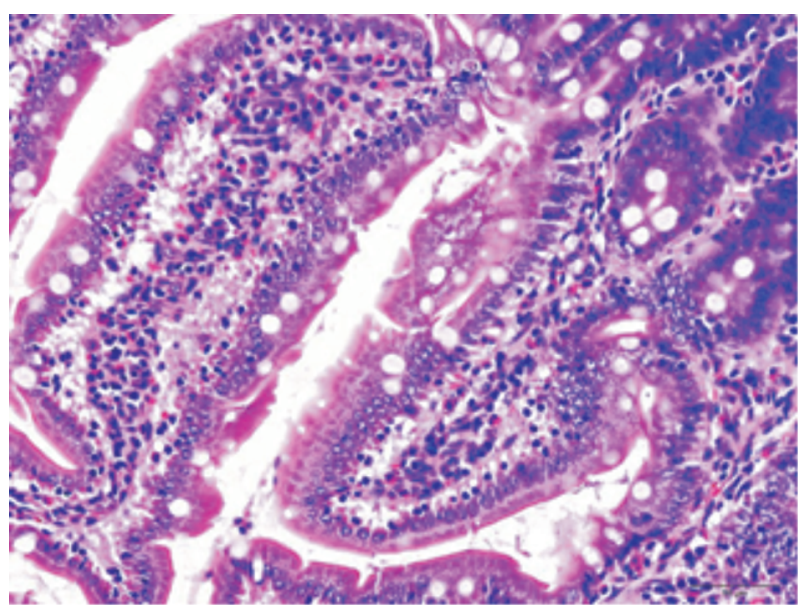

Fig 2. Small intestine mucosa -infiltration of lymphocytes, plasmocytes and eosinophils. Edema of intestinal villi. HE, $\mathrm{x} 40$.

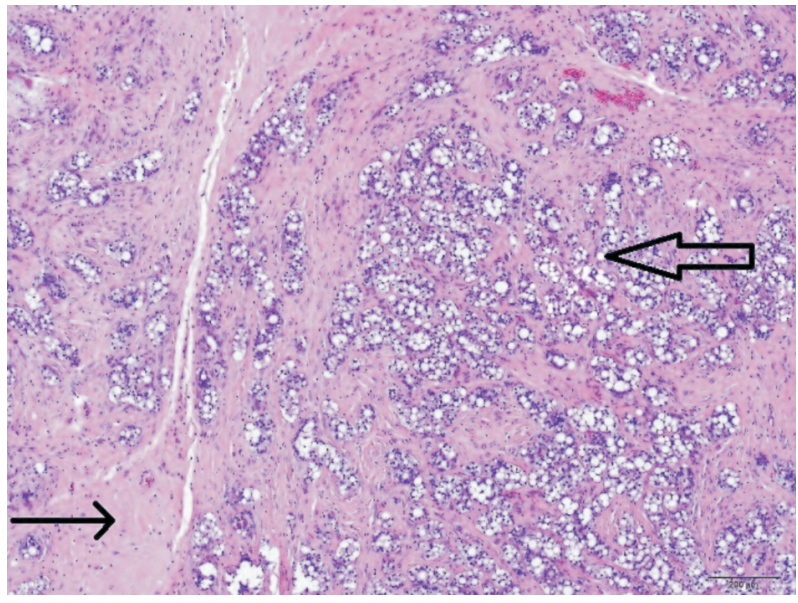

Fig. 3. Adenofibroma of mammary gland of rat. Abundant connective tissue (thin arrow) and glandular part (thick arrow) with milk stones, HE, $x 40$.

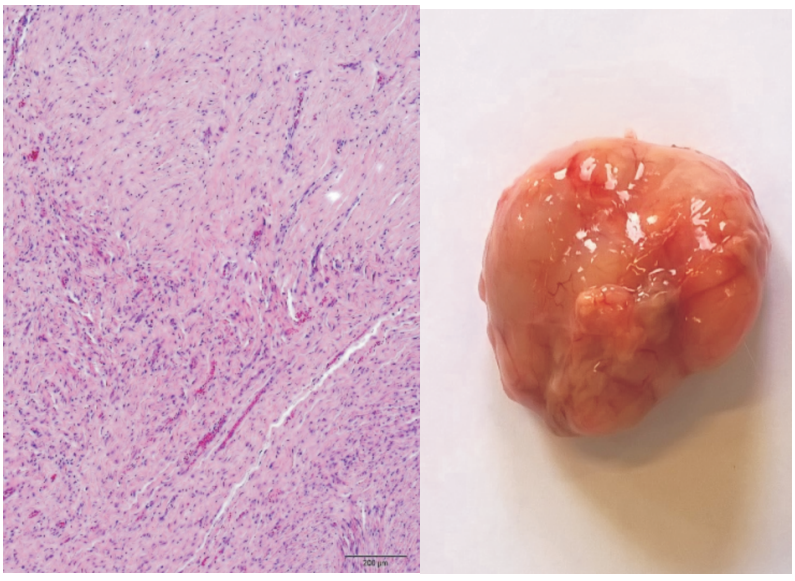

Fig. 4. Subdermal fibroma in rat - at left HE, $x 40$; at right - gross view.

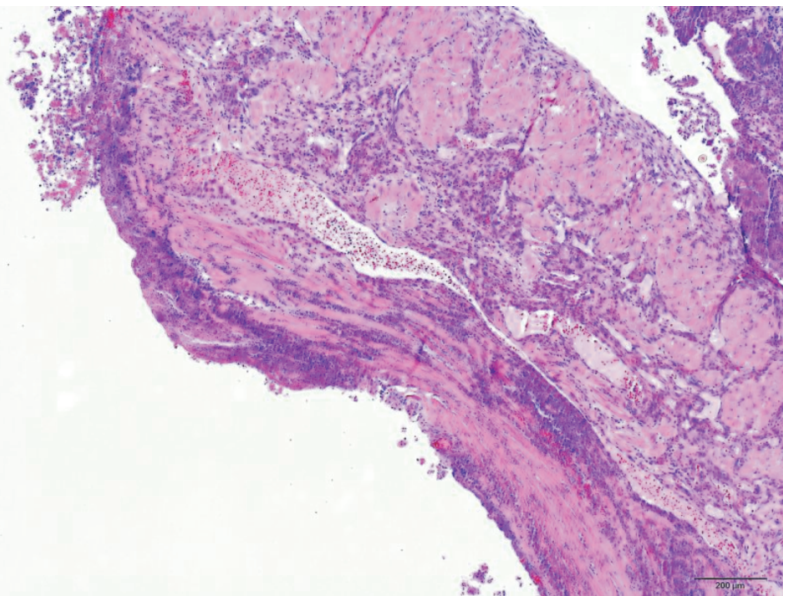

Fig. 5. Purulent inflammation of rat uterus (endometritis, miometritis and perimetritis) with fetus putrification, HE, $\mathrm{x} 40$.

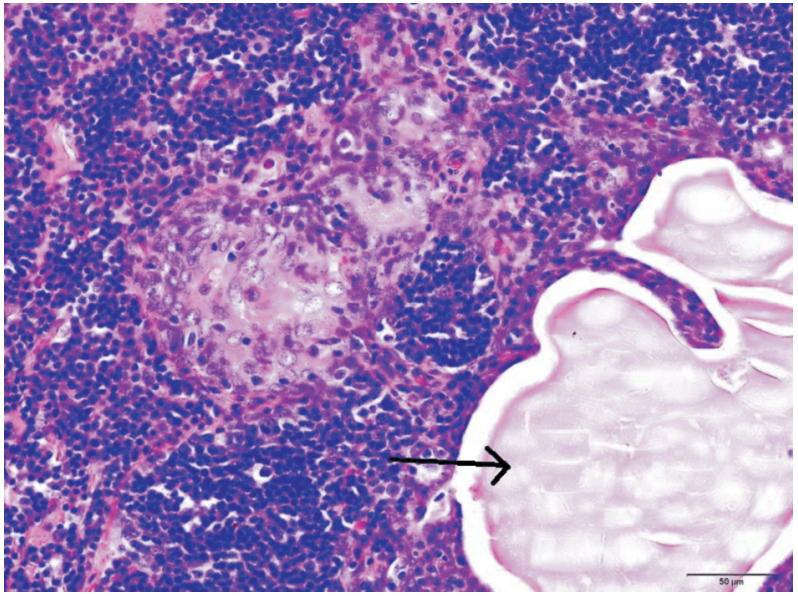

Fig. 6. Hyperplasia and cysts (arrow) formation in rat thymus. HE, x200. 


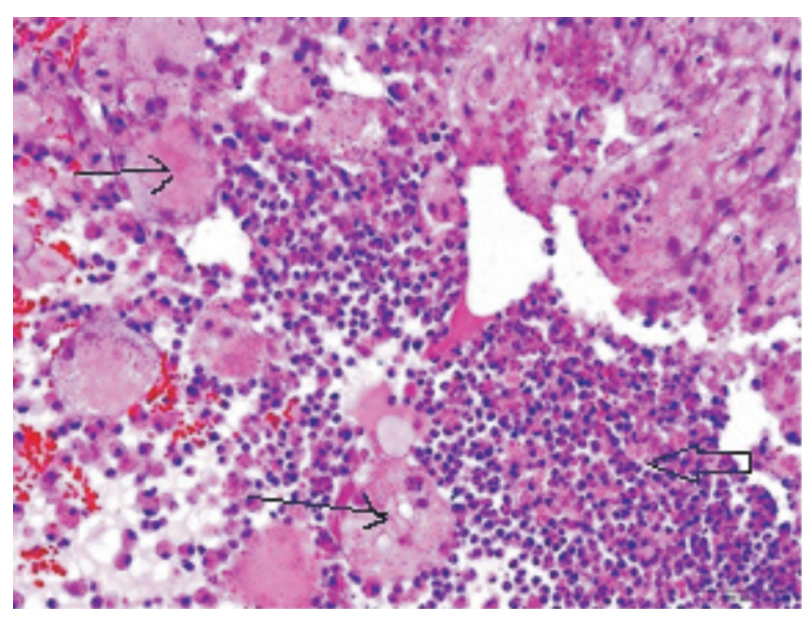

Fig. 7. Purulent exudate in rat bronchiole: abundant neutrophils (upper arrow) and macrophages (lower arrows) are visible. HE, x200.

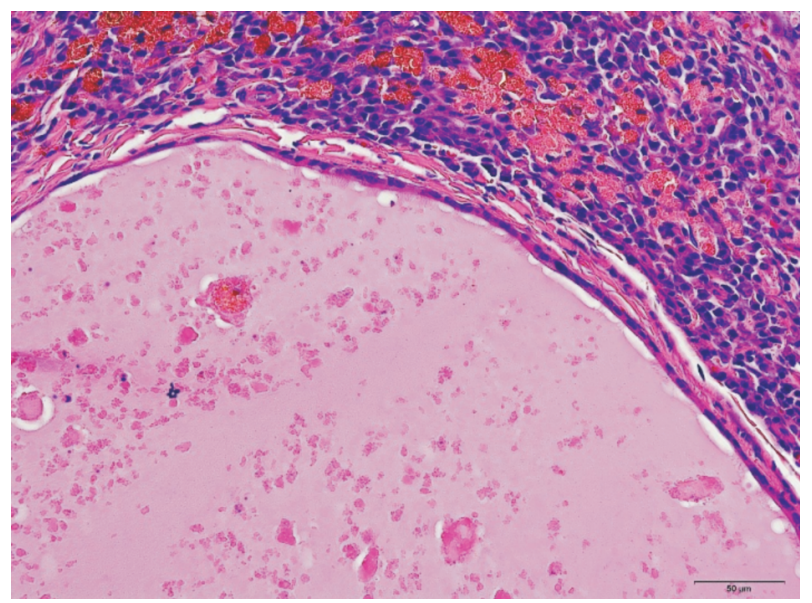

Fig. 8. Bronchiectasis in rat lung. Bronchiol diameter is enlarged, filled with mucoid - purulent exudate. Lung tissue around bronchiole is atelectatic and hyperemic. HE, x200.

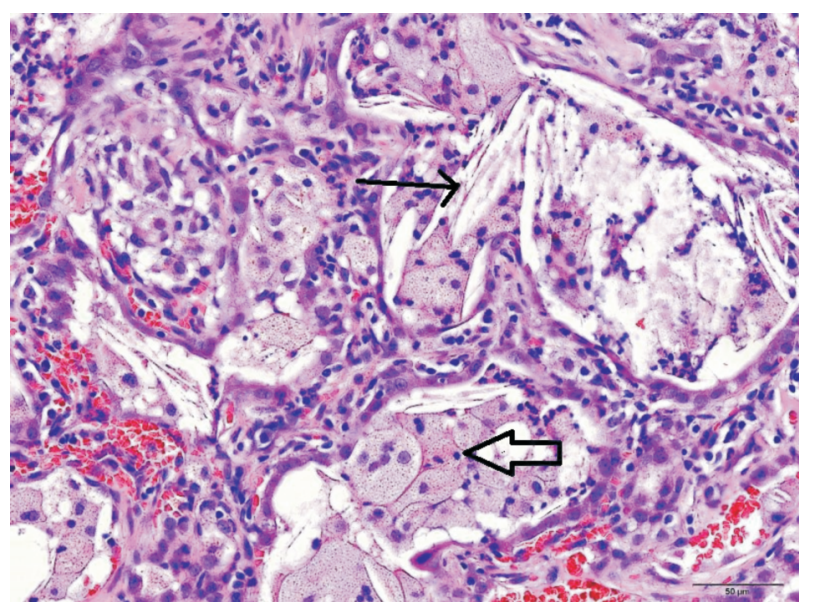

Fig. 9. Cholesterol crystal (thin arrow) formation in rat lung between macrophages (thick arrow). HE, x200.

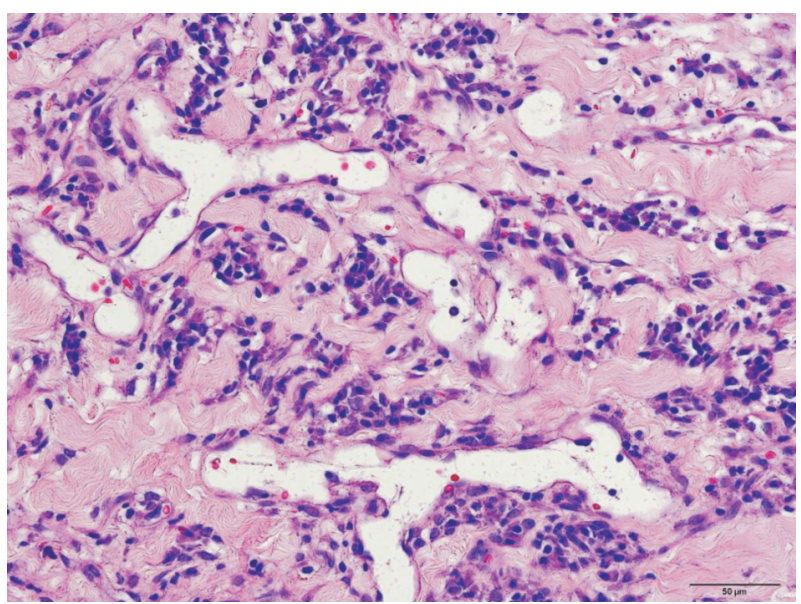

Fig. 10. Granulation tissue formation in periphery of abscess. $\mathrm{x} 200$.

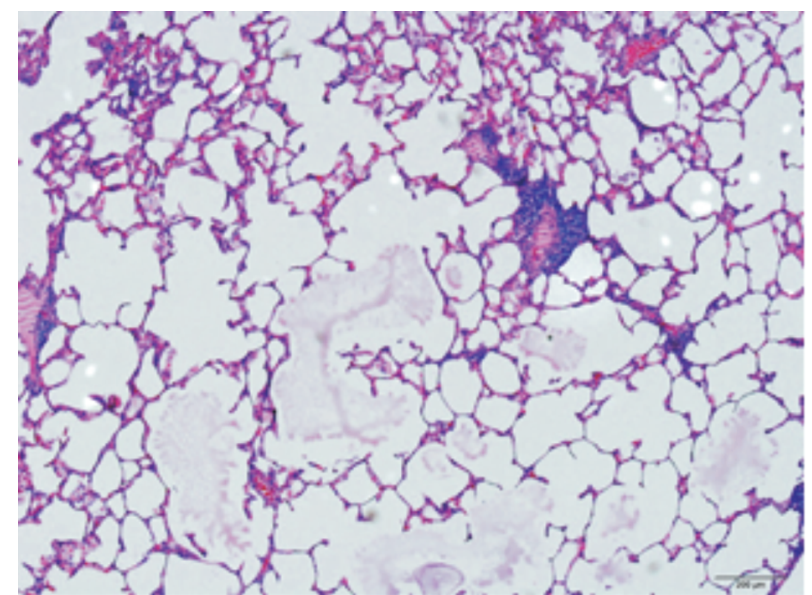

Fig. 11. Emphysema in rat lung. HE, $\mathrm{x} 40$.

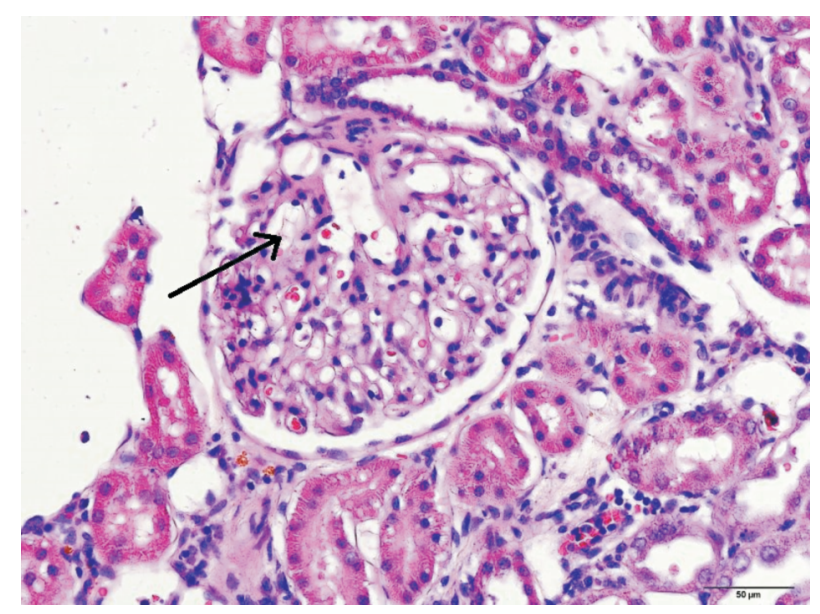

Fig. 12. Vacuolization of podocytes in rat kidney (black arrow). HE, x200. 


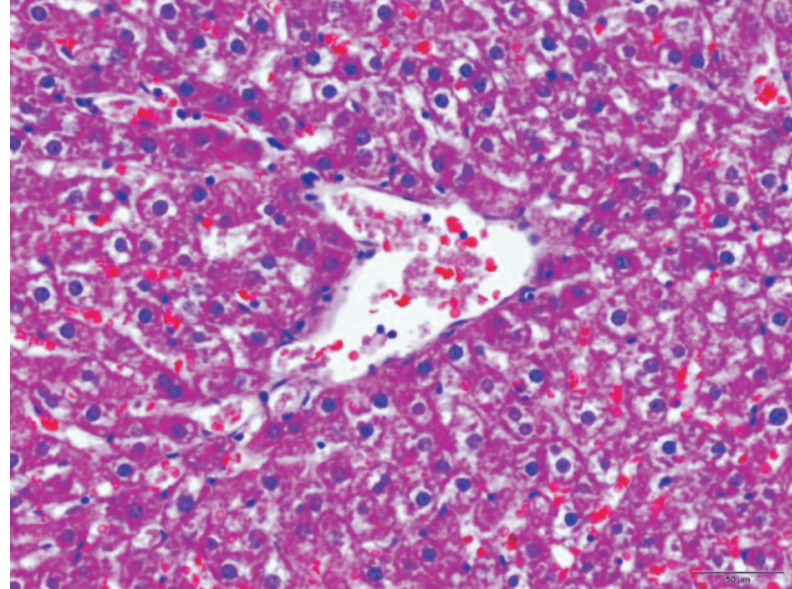

Fig. 13. Cell swelling and lipidosis in rat liver. HE, x200.

(33.3\%). Histopathological lesions are shown in Fig. 12.

The main changes in the liver were edema $(66.7 \%)$ and lipidosis (25\%). Histopathological changes are presented in Fig. 13.

\section{Discussion}

Many laboratories have found that nearby construction or building maintenance has produced a downturn in breeding success or noticeable disturbance of their animals. Chronic sources of sound in the laboratory may include ventilation, building noise, animal noise, and human noise (Patterson-Kane and Farnworth 2006). Long-term or short-term exposure to sound pollution disrupts many physiological functions in different systems of the body in humans and animals (Stansfeld and Matheson 2003, Kivimäki et al. 2006, Yildirim et al. 2007).

The different kinds of stress can cause reduction of body weight in experimental animals (Gamaro et al. 2003, Bekris et al. 2005, Zardooz et al. 2006, Lucca et al. 2009). In the present study, the weight of Wistar rats exposed to construction noise for one year was less in comparison to the rats kept under normal noise level. This could be related to insufficient digestion and absorption of nutrients because of inflammatory processes in the intestinal mucosa found during histopathological examination.

Several studies reported higher haemoglobin and RBC values (Ola-Davies et al. 2014, Vinodini et al. 2015), and lower WBC values (Osonuga et al. 2012) in rats of Wistar strain than we found. Ashaolu et al. (2011) determined similar results to ours for RBC counts in the blood of Wistar rats. The present study demonstrated that the WBC count decreased in rats exposed to excessive noise (group I) compared to the rats in the control (group II). Erken at al. (2008) claimed that a $95-\mathrm{dB}$ machine sound changes the haematological parameters of rats such as red blood cell deformability and aggregation. Moreover, long-term noise exposure could lead to an increase in the number of red blood cells, and serum concentration of haemoglobin (Monsefi et al. 2006, Wankhar et al. 2014).

It was noted that total protein content and albumin value of blood were higher, but blood urea nitrogen was lower in group I compared to the group II. These results are in line with Kadi et al. (2014); however, several studies detected a higher content of total protein (Ola-Davies et al. 2014, Vinodini et al. 2015). The increased protein and albumin levels indicate impairment in the normal function of the liver, as recently revealed (Imafidon and Okunrobo 2012); it seems that long-term construction noise exposure changes the normal functions of the rat liver.

The enzymatic activity of ALT and AST were studied to evaluate liver malfunctions. Liver enzyme levels are usually raised in acute hepatoxicity, but tend to decrease with prolonged intoxication due to damage to the liver (Obi et al. 2004). In the present study AST enzyme activity of blood was three times higher compared to the results of Ola-Davies et al. (2014). Moreover, similar results of ALT activity were reported by Kadi et al. (2014) and Ola-Davies et al. (2014).

Rahma (2011) reported that noise of 80-100 dBA caused a significant increase in plasma glucose of rats but the cholesterol and triglycerides have no significant difference compared to control. Rostamkhani et al. (2012) observed a non-significant reduction of plasma triglyceride, and unchanged concentration of glucose and plasma cholesterol following chronic stress exposure compared to the control. No changes in the serum level of glucose in rats exposed to chronic noise were noticed by Armario et al. (1985). We found that rats exposed to long-term construction noise had a significantly lower content of Glu compare to the rats kept under normal noise level. However, no differences in the serum concentration of TG and $\mathrm{T}$-Cho were noticed. If the stress continues for a long period it may be possible that the stress response of the animals become "distress", in which apparent precipitation or exacerbation of metabolic impairments may occur (Dhabhar and McEwen 1997).

In our study we observed pathological changes in the rat intestinum and lungs. Mainly inflammation was noted. In association with this there were changes in immune system organs such as lymph nodes, but less in the thymus. This may be related to disbacteriosis due to stress. The changes in biological function occurring during a stress response may suppress immune competence, rendering the animal susceptible 
to pathogens that may be present in the environment (Moberg, 2000). All experiments of Baldwin (2007) demonstrated that $90 \mathrm{~dB}$ white noise reduced stimulation of the parasympathetic nervous system, and also induced an inflammatory response in the intestinal mucosa, resulting in structural damage.

Kleessen et al. (1999) noticed that rats are sensitive to multifactorial disorders. Microbial dysbiosis in the caecum leads to changes in the digestive system which could promote the development of potentially pathogenic microflora, which could cause digestive troubles, which might have similar effects on the health status: intestinal health, caecal characteristics and microflora population. Rats are coprophagic and ingest a large number of bacteria along the whole gastrointestinal tract. The large intestine contains a complex bacteria flora, with the principal groups being the Enterobacteria, enterococci, lactobacilli, bacteroides species and bifidobacteria. The strictly anaerobic bacteria (bacteroides, bifidobacteria), which outnumber the aerobes (enterobacteria, enterococci) by a factor 100 to 1000 , are present in large numbers in rats. In the intestine the most numerous organisms are lactobacilli, bacteroides species and bifidobacteria $\left(10^{6}-10^{8} \mathrm{CFU} / \mathrm{ml}\right.$ which outnumber the enterobacteria by a factor of more than 100). Stress causes hypothalamic-pituitary-adrenal (HPA) axis activation and gut microbiota dysbiosis (Galley and Bailey, 2014). The activation of the HPA axis produces changes in certain populations of bacteria (Pullinger et al. 2010).

Fewer changes were determined in the reproductive system. Only one rat had abortus with putrificated fetuses and inflammation of the uterus. Stress can suppress reproduction. Nakamura et al. (1996) noticed that mechanically induced whole-body vibration of 9-11 day gestation female Wistar rats resulted in decreased uterine blood flow, increases in plasma corticosterone, and decreases in plasma progesterone and prostaglandin E2, but no changes were found in plasma estradiol and prostaglandin F- compered to control rats. In contrast our studied rats were 18 months old, and according Hung et al. (2003) reproductive aging in female rats results from both aging and estrogen exposure, and may be rooted in the oxidative stress theory of aging.

Our study of rats showed different levels of degeneration (swelling, lipidosis) in the liver and kidney. These pathologies can be in association with inflammation processes in other organs and while the cells of the hepatic parenchyma have the flexibility to adapt to changing physiological demands, with reversible functional and morphological alterations, sufficient stress or noxious stimuli may lead to inability to main- tain homeostasis and adverse cellular adaptations. The morphological response to injurious stimuli depends on the nature of the injury and its severity and duration (Thoolen et al. 2010). Helal et al. (2011) detected that noise exposure showed some vacuolated hepatocytes with enlarged nuclei of the endothelial lining compared with the control group. Xue et al. (2014) indicated that noise could lead to pathological changes in the liver because the exposure to noise increased the level of oxygen free radicals and lipid peroxidation. They consider that the possible mechanism was that the rats were in a state of stress when they were exposed to noise, and therefore under this condition the oxygen free radicals in the body and malondialdehyde (a product of oxygen free radicals) content would be higher than normal.

We diagnosed spontaneous cases of neoplasms in rat subcutis (fibroma) and mammary gland (adenofibroma). In many studies, a major cause of death of rats is neoplasms. In some rat studies, benign and malignant cutaneous and subcutaneous neoplasms are a common cause of death (Snyder et al. 2016). Fibromas are the most common tumor of the subcutis at about 5\% incidence in male Fischer 344 and Wistar rats (Poteracki and Walsh 1998, Suckow et al. 2006). According to Suckow et al. (2006) primary tumors of the mammary gland are some of the most common tumors in rats occurring in up to a third of females by 2 years of age. In our study we found mammary gland tumors by 18 months of age. For Wistar rats and Fischer 344, the majority of tumours are fibroadenomas. Boorman et al. (1990), Poteracki and Walsh (1998) reported that fibroadenomas were the most common mammary tumor $(43 \%$ of all integumentary tumors, $78 \%$ of all mammary tumors).

\section{Conclusion}

From the results of this study it can be concluded that long-term construction noise from building refurbishment has an influence on body weight, haematological and some serum biochemical parameters, caecum mibrobiota, and histopathological changes in the organs of adult female Wistar rats. The most common pathologies where determined in the kidney, liver and lungs. Other pathologies were lymphadenopathy, catarrhal inflammation of the intestines, spleen hyperplasia and mammary gland adenofibroma. There were single cases of subcutaneous fibroma in the thoracic region, abortus with uterine inflammation, and thymus hyperplasia with cyst formation. 


\section{References}

Armario A, Castellanos JM, Balasch J (1985) Chronic noise stress and insulin secretion in male rat. Physiol Behav 34: 359-361.

Ashaolu JO, Ukwenya VO, Okonoboh AB, Ghazal OK, Jimoh AA (2011) Effect of monosodium glutamate on hematological parameters in Wistar rats. Int J Med Med Sci 3: 219-222.

Baldwin AL (2007) Effects of Noise on Rodent Physiology. Int J Comp Psychol 20: 134-144.

Bekris S, Antoniou K, Daskas S, Papadopoulou-Daifoti Z (2005) Behavioural and neurochemical effects induced by chronic mild stress applied to two different rat strains. Behav Brain Res 161: 45-59.

Bjork E, Nevalainen T, Hakumaki M, Voipio HM (2000) R-weighting provides better estimation for rat hearing sensitivity. Lab Anim 34: 136-144.

Boorman GA, Wilson JT, van Zwieten MJ, Eustis SL (1990) Mammary gland. In: Boorman GA, Eustis SL, Elwell MR, Montgomery CA, MacKenzie WF (eds) Pathology of the Fischer Rat. Academic Press, London, pp 295-337.

Burn CC (2008) What is it like to be a rat? Rat sensory perception and its implications for experimental design and rat welfare. Appl Anim Behav Sci 112: 1-32.

Castelhano-Carlos MJ, Baumans V (2009) The impact of light, noise, cage cleaning and in-house transport on welfare and stress of laboratory rats. Lab Anim 43: 311-327.

Clough G (1982) Environmental effects on animals used in biomedical research. Biol Rev Camb Philos Soc 57: 487-523.

Dhabhar FS, McEwen BS (1997) Acute stress enhances while chronic stress suppresses cell-mediated immunity in vivo: a potential role for leukocyte trafficking. Brain Behav Immun 11: 286-306.

Helal EG, Eid F, Taha NM (2011) Effect of noise stress and /or sulpiride treatment on some physiological and histological parameters in female albino rats. Egypt $\mathbf{J}$ Hosp Med 44: 295-310.

Erken G, Bor Kucukatay M, Erken HA, Kursunluoglu R, Genc O (2008) Influence of classical and rock music on red blood cell rheological properties in rats. Med Sci Monit 14: BR28-33.

Galley JD, Bailey MT (2014) Impact of stressor exposure on the interplay between commensal microbiota and host inflammation. Gut Microbes 5: 390-396.

Gamaro GD, Manoli LP, Torres IL, Silveira R, Dalmaz C (2003) Effects of chronic variate stress on feeding behavior and on monoamine levels in different rat brain structures. Neurochem Int 42: 107-114.

Gamble MR (1982) Sound and its significance for laboratory animals. Biol Rev Camb Philos Soc 57: 395-421.

Hung AJ, Stanbury MG, Shanabrough M, Horvath TL, Garcia-Segura LM, Naftolin F (2003) Estrogen, synaptic plasticity and hypothalamic reproductive aging. Exp Gerontol 38: 53-59.

Imafidon KE, Okunrobo LO (2012) Study on Biochemical Indices of Liver Function Tests of Albino Rats Supplemented with Three Sources of Vegetable Oils. Nig J Basic Appl Sci 20: 105-110.

Kadi FZ, Bénali AI, Benali M, Belbraouet S (2014) Effect of sodium metabisulphite on blood metabolic status of Wistar rats. Food Nutr Sci. 5: 1529-1537.
Kelly JB, Masterton B (1977) Auditory sensitivity of the albino rat. J Comp Physiol Psychol 91: 930-936.

Kivimäki M, Virtanen M, Elovainio M, Kouvonen A, Väänänen A, Vahtera $\mathbf{J}$ (2006) Work stress in the etiology of coronary heart disease - a meta-analysis. Scand J Work Environ Health 32: 431-442.

Kleessen B, Stoof G, Proll J, Schmiedl D, Noack J, Blaut M (1997) Feeding resistant starch affects fecal and cecal microflora and short-chain fatty acids in rats. J Anim Sci 75: 2453-2462.

Leensen MC, van Duivenbooden JC, Dreschler WA (2011) A retrospective analysis of noise-induced hearing loss in the Dutch construction industry. Int Arch Occup Environ Health 84: 577-590.

Lucca G, Comim CM, Valvassori SS, Reus GZ, Vuolo F, Petronilho F, Dal-Pizzol F, Gavioli EC, Quevedo J (2009) Effects of chronic mild stress on the oxidative parameters in the rat brain. Neurochem Int 54: 358-362.

Moberg GP (2000) Biological Response to Stress: Implications for Animal Welfare. In: Moberg GP, Mench JA (eds) The biology of animal stress: basic principles and implications for animal welfare. CABI Publishing, Oxon, United Kingdom, pp 1-21.

Monsefi M, Bahoddini A, Nazemi S, Dehghani GA (2006) Effects of noise exposure on the volume of adrenal gland and serum levels of cortisol in rat. Iran J Med Sci 31: 5-8.

Nakamura H, Ohsu Y, Nagase H, Okazawa T, Yoshida M, Okada A (1996) Uterine circulatory dysfunction induced by whole-body vibration and its endocrine pathogenesis in the pregnant rat. Eur J Applied Physiol Occup Physiol 72: 292-296.

$\mathrm{Ng}$ CF (2000) Effects of building construction noise on residents: a quasi-experiment. J Environ Psychol 20: 375-385.

Obi E, Orisakwe OE, Asomugha LA, Udemezue OO, Orish VN (2004) The hepatotoxic effect of halofantrine in guinea pigs. Indian J Pharmacol 36: 303-305.

Ola-Davies OE, Olukole SG, Amoo OA (2014) Haematological and serum biochemical variables in rats treated with ethanol extract of the root of Moringa oleifera. Afr J Biomed Res 17: 31-35.

Osonuga IO, Osonuga OA, Osonuga A, Onadeko AA, Osonuga AA (2012) Effect of artemether on hematological parameters of healthy and uninfected adult Wistar rats. Asian Pac J Trop Biomed 2: 493-495.

Patterson-Kane EG, Farnworth MJ (2006) Noise exposure, music, and animals in the laboratory: a commentary based on Laboratory Animal Refinement and Enrichment Forum (LAREF) discussions. J Appl Anim Welf Sci 9: 327-332.

Poteracki J, Walsh KM (1998) Spontaneous neoplasms in control Wistar rats: a comparison of reviews. Toxicol Sci 45: 1-8.

Pullinger GD, van Diemen PM, Carnell SC, Davies H, Lyte M, Stevens MP (2010) 6-hydroxydopamine-mediated release of norepinephrine increases faecal excretion of Salmonella enterica serovar Typhimurium in pigs. Vet. Res 41: 68.

Rahma MS (2011) The effects of noise on biochemical parameters using rats' hearts. Eur J Sci Res 56: 93-96.

Rostamkhani F, Zardooz H, Zahediasl S, Farrokhi B (2012) Comparison of the effects of acute and chronic psychological stress on metabolic features in rats. J Zhejiang Univ Sci B 13: 904-912. 
Snyder JM, Ward JM, Treuting PM (2016) Cause-of-Death Analysis in Rodent Aging Studies. Vet Pathol 53: 233-243.

Stansfeld SA, Matheson MP (2003) Noise pollution: non-auditory effects on health. Br Med Bull 68: 243-257.

Suckow MA, Weisbroth SH, Franklin CL (2006) The laboratory rat. 2nd ed. Elsevier Academic Press, San Diego, CA.

Suter AH (2002) Construction noise: exposure, effects, and the potential for remediation; a review and analysis. AIHA J (Fairfax, Va) 63: 768-789.

Thoolen B, Maronpot RR, Harada T, Nyska A, Rousseaux C, Nolte T, Malarkey DE, Kaufmann W, Küttler K, Deschl U, Nakae D, Gregson R, Vinlove MP, Brix AE, Singh B, Belpoggi F, Ward JM (2010) Proliferative and nonproliferative lesions of the rat and mouse hepatobiliary system. Toxicol Pathol 38 (Suppl 7): 5S-81S.

Turner JG, Parrish JL, Hughes LF, Toth LA, Caspary DM (2005) Hearing in laboratory animals: strain differences and nonauditory effects of noise. Comp Med 55: 12-23.

Vinodini NA, Chatterjee PK, Chatterjee P, Chakraborti S, Nayanatara AK, Bhat RM, Rashmi KS, Suman VB,
Shetty SB, Pai SR (2015) Protective role of aqueous leaf extract of Moringa oleifera on blood parameters in cadmium exposed adult Wistar albino rats. Int $\mathrm{J}$ Curr Res Aca Rev 3: 192-199.

Voipio HM (1997) How do rats react to sound? Scand J Lab Anim Sci 24: 1-80.

Wankhar D, Sheela Devi R, Ashok I (2014) Emblica officinalis outcome on noise stress induced behavioural changes in Wistar albino rats. Biomed Prev Nutr 4: 219-224.

Yildirim I, Kilinc M, Okur E, Inanc Tolun F, Kilic MA, Kurutas EB, Ekerbiçer HC (2007) The effects of noise on hearing and oxidative stress in textile workers. Ind Health 45: 743-749.

Xue L, Zhang D, Yibulayin X, Wang T, Shou X (2014) Effects of high frequency noise on female rat's multi-organ histology. Noise Health 16: 213-217.

Zardooz H, Zahedi Asl S, Naseri GM (2006) Effect of chronic psychological stress on insulin release from rat isolated pancreatic islets. Life Sci 79: 57-62. 